\title{
COMPARATIVELY ASSESSING THE USE OF BLACKBOARD VERSUS DESIRE2LEARN: STUDENT PERCEPTIONS OF THE ONLINE TOOLS
}

\author{
Adnan A. Chawdhry, California University of Pennsylvania, chawdhry_a@calu.edu \\ Karen Paullet, American Public University System, kp1803@online.apus.edu \\ Daniel Benjamin, American Public University System, dbenjamin@apus.edu
}

\begin{abstract}
Current trends indicate that an increasing number of Universities have been offering online classes without assessing the online learning management tools to understand the students' perspective of the technology.. When a University understands the student perception they can implement an online education environment that is conducive to student learning. This paper provides a quantitative and comparative assessment of Blackboard and Desire2Learn, two tools used to implement online classes. These tools were utilized at a small rural Mid-Atlantic university in the 2010 and 2011 academic years. A survey was distributed to the undergraduate and graduate student populations to understand their opinions about Blackboard and Desire2learn, and to assess the difference in their preferences between these two technologies. The students who participated had experienced both tools at this university. This survey was based upon a study that was conducted at the University of Denver in 2006. The results of the survey were analyzed to better understand the students' perceptions of these technologies and what features were commonly used. However, no significant differences or variances were found between the two technologies.
\end{abstract}

Keywords: Blackboard, Desire2Learn, Online Classes, Online Learning, Distance Education, Learning Management System, LMS

\section{INTRODUCTION}

All over the world, universities and colleges use network technologies to implement collaborative, online courses in higher education. Online learning makes universities more accessible to larger student populations; it enables students who are unable to physically attend classes on campus to participate in the program. Online learning has become an educational alternative to traditional learning styles.

Online education is expanding at a rapid pace. Since 2003, online enrollments have been growing substantially faster than that of traditional higher education enrollments [1]. The online student population has increased more rapidly than the total higher education student population. As of fall 2009, one in every four students had registered for at least one online course [1]. With the growing demand for online courses, it is necessary for universities to provide students with the most optimal learning environment. For the purpose of this study the researchers conducted a comparative analysis of university student's perceptions of Blackboard versus Desire2Learn (D2L).

\section{LITERATURE REVIEW}

Online learning is growing at a rapid pace. Advances in technology and the Internet have changed the way people access and use information. A recent 2010 online education study conducted by Allen and Seaman revealed that 5.6 million students were taking at least one online course during the fall 2009 term; an increase of nearly one million students over the corresponding number reported the previous year. This 21 percent growth rate in online education far exceeds the almost two percent growth rate in the overall higher education student population. Nearly 30 percent of higher education students now take at least one online class [1]. This trend shows that an increasing number of people are enrolling in distance learning programs to complete their degrees in order to compete in today's job market and to advance in their careers. 
In the same study on online education conducted by Allen and Seaman 63 percent of Chief Academic Officers indicated that online education is critical to their long term strategy. Data indicates that this is an increase from 2009 to 2010 and that private for-profit-institutions are driving this change [1].

According to Blackboard, [2] students experience enhanced learning experience when using collaborative online tools featured in its web-based learning management system. The web-based tools in Blackboard to enhance communication and interaction between class members and faculty include discussion boards, online forums, email, and chat rooms. The online forums enable students to share their analyses, perspectives, and experiences with their peers and instructors. Blackboard enables instructors to adapt their assignments, discussion boards, and in effect the overall teaching environment to the various learning styles of the students with the use of collaboration, interactivity, graphics, audio, and video. Course materials are available to students twenty-four hours a day, seven days a week in Blackboard; this feature enables students to access and participate in their education at their convenience. Students can balance the demands on their time and also maximize the classroom learning experience.

A 2010 study conducted by the researchers on improving online instructional delivery by accessing Blackboard revealed that 31 percent of students at a mid-Atlantic university in Pennsylvania prefer taking classes online. The reasons that students chose online as their preferred method of taking courses included, time constraints, learning style, and learning effectiveness. Students listed $24 x 7$ access to course materials and the overall accessibility to the online system as one of the strongest benefits for taking online classes [4].

The University of Denver's Center for Teaching and Learning's Courseware Faculty Advisory Board (CFAB) completed a study of their student's perceptions of Blackboard [3]. Of the total 1,821 students completed that completed the survey nearly 90 percent attested that Blackboard was an excellent web-based tool. Fewer than two percent reported having a bad experience with Blackboard. The number one reason that students liked Blackboard was the access to the course materials at all times. They also noted that there was a high level of communication with their instructors. Other benefits included the immediate access to their grades, improved class discussions, and the ability to view assignments. Approximately 82 percent of students preferred courses that utilize Blackboard or other web-based tools as compared to 10 percent that did not [3].

A study conducted by Hannay and Newvine [5] indicated that students prefer online education because it allows them to balance their life demands while going to school. The researchers sought to determine the reasons for the students' interest in distance learning and allowed students to select more than one option as the basis for their decision to attend an online program. Twenty percent of the participants chose distance learning because the courses necessary to complete their degrees were only offered at limited times in the brick and mortar schools but were scheduled more often in the world of online education. Approximately 88 percent of students chose distance learning because they had other life and academic commitments that precluded them from physically attending courses on campus. Also, 59 percent of students surveyed reported that their grades were higher in distance learning than in traditional courses and 70 percent of students indicated that they preferred online courses. A particularly interesting finding was that 90 percent of students read the textbooks associated with their online courses as compared to just 60 percent of students that read the textbooks in traditional classes.

In a 2010 study conducted by the researchers on student's perceptions of using Blackboard, 89 percent of students preferred online classes because it accommodated their time constrains, was easy to use, and improved their communication with the instructor. Of the students that prefer online learning, seven percent were dissatisfied with the use of Blackboard because it was rarely kept up-to-date and because the interface was poorly designed [4].

As of fall 2010, the entire Pennsylvania State System for Higher Education (PASSHE) transitioned from Blackboard to Desire2Learn (D2L). After a comprehensive review process by PASSHE, Desire2Learn turned out to be the overwhelming choice. Desire2Learn provided more tools and capabilities than Blackboard and featured a friendlier user interface for both faculty and students. One of the deciding factors was that it took about a third of the clicks to accomplish tasks in Desire3Learn as compared to Blackboard [7].

According to Kovacs, et.al, there is little doubt that changes in higher education are being driven by technological advances in sophisticated communication technologies and the media-rich extensions of the Internet. These 
technological advances have prompted universities to use alternatives to the traditional classroom teaching and learning methods and have allowed new developments in the way faculty deliver course content to their students. These new developments have resulted in the growth of a new paradigm in pedagogy; technology-enabled learning environments [6].

\section{RESEARCH METHODOLOGY}

The online learning environment enables students all over the world to access higher education; it also allows students to access classes at their own convenience day or night. The purpose of this study is to compare the students' perceptions of Blackboard with that of Desire2Learn. This study explores the following research questions: RQ1: What is the technology preference of students who have used Blackboard and Desire2Learn?

RQ2: Is there a significant difference of using Blackboard between Desire2Learn when taking online classes?

This study examined student perceptions of Blackboard as compared to Desire2Learn, at a small mid-Atlantic University during the months of February and March 2011. This study utilized a quantitative methodology to assess the differences between Blackboard and D2L. The population chosen for the student survey was comprised of undergraduate and graduate students.

Undergraduate and graduate students were surveyed in order to gather data from students 18 years of age or older. The survey was conducted using Survey Monkey, an online survey tool. A total of 246 residential and nonresidential students completed the survey.

The survey questions focused on obtaining information from students who had used both Blackboard and Desire2Learn. The survey was developed from a partial replication of a 2006 [3] Blackboard survey conducted at the University of Denver and an earlier study conducted by the researches at a mid-Atlantic University in Pennsylvania in 2010. The researchers enhanced the survey with additional questions to obtain insights that were not captured in the prior studies. The survey results were analyzed using SPSS, a software tool for statistical analysis. This study used Chi-square with a statistical significance at the .05 margin of error with a $95 \%$ confidence level to determine students' preference of Blackboard or Desire2Learn. Statistical frequencies were used to determine the basis for the students' use of the two online learning systems. The study was a convenience samplesurveying students' from the School of Arts and Humanities, Business, Science and Match, Engineering, Computer Science, Information Technology, Criminal Justice and Psychology.

The survey instrument consisted of 27 closed-ended questions and one open-ended question. Fourteen of the closedended questions provided an "Other" option, which allowed students to provide responses in addition to predetermined responses listed in each question. The first four questions focused on student demographics; they included gender, age, education, and degree program. Question five, was a contingency question that asked students if they had taken any online distance learning classes. If the students answered yes, they continued to question six which asked if the students had taken online classes using both Blackboard and Desire2Learn. If the students answered yes again, they were to continue with the survey. If the answer was no, the student exited the survey. Based on the students' knowledge and use of both Blackboard and Desire2Learn, questions 7-26 focused on their preferences between the two online management systems. The final question was designed so that students could provide any additional comments or concerns related to Blackboard or Desire2Learn.

\section{RESULTS}

The survey responses were analyzed to assess the students' technology preference for Blackboard as compared to Desire2Learn and to determine if the difference in preferences was significant. The student responses indicated that $61.3 \%$ of the respondents were female and $38.7 \%$ of the respondents were male. The demographic and background information was further detailed in relation to gender in Figure 1 and Table 1. Figure 1 breaks down the percentage of males and females according to their education level. The senior and junior standing students for had the highest response rate for both males and females. Table 1 depicts the age, education, level, desired degree, and prior experience with online classes broken down by gender. 


\section{Issues in Information Systems}

Volume XII, No. 2, pp 273-280, 2011

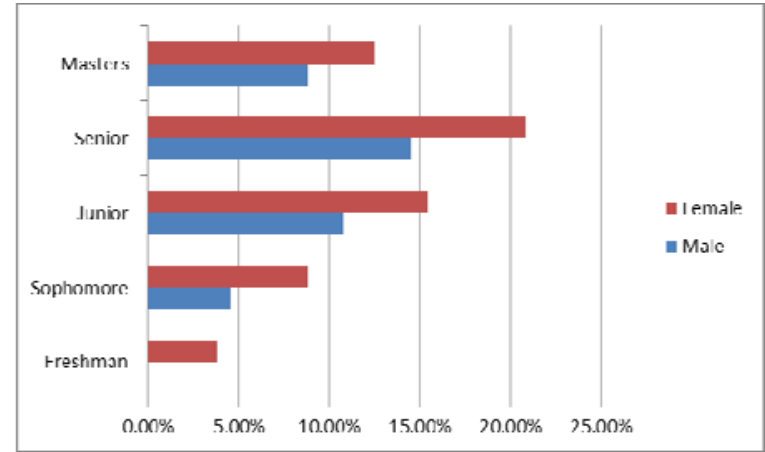

Figure 1: Education Level Broken Down by Gender

Table 1: Demographic Breakdown of Survey

\begin{tabular}{lcc}
\multicolumn{3}{c}{ Participants } \\
\hline Demographic & $\underline{\text { Male }}$ & Female \\
\hline Information & & \\
\hline Age: & $25.4 \%$ & $38.7 \%$ \\
$\mathbf{1 8 - 2 5}$ & $5.0 \%$ & $14.2 \%$ \\
$\mathbf{2 6 - 3 5}$ & $4.2 \%$ & $6.3 \%$ \\
$\mathbf{3 6 - 4 5}$ & $3.3 \%$ & $2.1 \%$ \\
$\mathbf{4 6 - 5 5}$ & $.8 \%$ & $0.0 \%$ \\
$\mathbf{5 6 - 6 5}$ & & \\
Education Level: & $0.0 \%$ & $3.8 \%$ \\
Freshman & $4.6 \%$ & $8.8 \%$ \\
Sophomore & $10.8 \%$ & $15.4 \%$ \\
Junior & $14.5 \%$ & $20.8 \%$ \\
Senior & $8.8 \%$ & $12.5 \%$ \\
Masters & & \\
Degree: & $2.6 \%$ & $3.9 \%$ \\
Arts and Humanities & $18.4 \%$ & $23.8 \%$ \\
Business & $3.4 \%$ & $11.7 \%$ \\
Education & $7.8 \%$ & $15.5 \%$ \\
Science \& Math & $1.3 \%$ & $0.4 \%$ \\
Computer Science & $2.6 \%$ & $0.4 \%$ \\
Information Systems & $1.3 \%$ & $1.3 \%$ \\
Information Technology & $0.4 \%$ & $3.0 \%$ \\
Psychology & $0 . .9 \%$ & $1.3 \%$ \\
Undecided & & \\
Online Classes Before & & \\
Yes & $32.5 \%$ & $49.8 \%$ \\
No & $6.2 \%$ & $11.5 \%$ \\
Total & $38.7 \%$ & $61.3 \%$ \\
\hline & & \\
\hline
\end{tabular}

After collecting the demographic data, the researchers collected data about the students' choices between Blackboard and Desire2Learn in relation to gender, age, education level, and degree. The first comparison focused on the students preferred choice for online class technology; this was broken down by male and female. The result yielded a chi-square value of .333 with one degree of freedom. Additionally, the statistical probability was calculated to be .564 or $56.4 \%$. Since this value did not fall below the required .05 or $5 \%$ threshold, the study did not find any statistical significance between gender and the students' choices of technology for their online classes. Table 2 lists the percentage of students (by gender) who chose the specific online class technology. 
Volume XII, No. 2, pp 273-280, 2011

Table 2: Technology Choice by Gender

\begin{tabular}{lccc}
\hline Gender & Blackboard & Desire2Learn & Total \\
\hline Male & $15.7 \%$ & $23.0 \%$ & $38.7 \%$ \\
Female & $21.2 \%$ & $40.1 \%$ & $61.3 \%$ \\
Total & $36.9 \%$ & $63.1 \%$ & $100.0 \%$ \\
\hline
\end{tabular}

The second comparison investigated the students; choice for online class technology; the variable in this case was age. The results yielded a chi-square value of 1.966 with four degrees of freedom. The statistical probability was calculated to be .742 or $74.2 \%$ which is above the allowable limit of $5 \%$. Therefore, this study did not find any statistical significance between age and the students' choice of technology for their online classes. Table 3 below lists the percentage of students (by age) who chose the specific online class technology.

Table 3: Technology Choice by Age

\begin{tabular}{lccc}
\hline Age & Blackboard & Desire2Learn & Total \\
\hline $\mathbf{1 8}-\mathbf{2 5}$ & $23.0 \%$ & $40.9 \%$ & $63.9 \%$ \\
$\mathbf{2 6 - 3 5}$ & $7.7 \%$ & $11.5 \%$ & $19.2 \%$ \\
$\mathbf{3 6 - 4 5}$ & $3.8 \%$ & $7.1 \%$ & $10.9 \%$ \\
$\mathbf{4 6}-\mathbf{5 5}$ & $2.2 \%$ & $3.3 \%$ & $5.5 \%$ \\
$\mathbf{5 6 - 6 5}$ & $0.5 \%$ & $0.0 \%$ & $0.5 \%$ \\
Total & $37.2 \%$ & $62.8 \%$ & $100.0 \%$ \\
\hline
\end{tabular}

The third comparison evaluated the student's level of education with their choice for the online class technology. The results of this comparison yielded a chi-square value of 6.649 with four degrees of freedom. The statistical probability was calculated to be .156 or $15.6 \%$, which is above the allowable limit of $5 \%$. The study concluded that there was no statistical significance between the students' education level and their choice of technology for online classes. Table 4 displays the students' technology preference according to their education level.

Table 4: Technology Choice by Education Level

\begin{tabular}{lccc}
\hline $\begin{array}{l}\text { Education } \\
\text { Level }\end{array}$ & Blackboard & Desire2Learn & Total \\
\hline Freshman & $0.5 \%$ & $1.6 \%$ & $2.1 \%$ \\
Sophomore & $2.1 \%$ & $9.8 \%$ & $11.9 \%$ \\
Junior & $7.6 \%$ & $17.4 \%$ & $25.0 \%$ \\
Senior & $15.8 \%$ & $20.7 \%$ & $36.5 \%$ \\
Masters & $10.9 \%$ & $13.6 \%$ & $24.5 \%$ \\
Total & $36.9 \%$ & $63.1 \%$ & $100.0 \%$ \\
\hline
\end{tabular}

The fourth and final comparison was between their expected degree and their choice of technology for their online classes. The results of this comparison yielded a chi-square value of 9.765 with eight degrees of freedom. The statistical probability was calculated to be .282 or $28.2 \%$, which is above the allowable limit of $5 \%$. The study concluded that there was no statistical significance between a student's expected degree and their choice of technology for online classes. Table 5 displays the student's degree versus their technology choice. 
Volume XII, No. 2, pp 273-280, 2011

Table 5: Technology Choice by Degree

\begin{tabular}{lccc}
\hline Concentration & Blackboard & Desire2Learn & Total \\
\hline Arts \& Humanities & $1.6 \%$ & $4.4 \%$ & $6.0 \%$ \\
\hline Business & $12.7 \%$ & $30.3 \%$ & $43.0 \%$ \\
\hline Education & $9.4 \%$ & $7.1 \%$ & $16.5 \%$ \\
\hline Science \& Math & $8.2 \%$ & $13.8 \%$ & $22.0 \%$ \\
\hline Computer Science & $0.6 \%$ & $1.6 \%$ & $2.2 \%$ \\
\hline Information Systems & $1.6 \%$ & $1.6 \%$ & $3.2 \%$ \\
\hline Information Technology & $1.6 \%$ & $1.6 \%$ & $3.2 \%$ \\
\hline Psychology & $.6 \%$ & $1.6 \%$ & $2.2 \%$ \\
\hline Undecided & $1.1 \%$ & $0.6 \%$ & $1.7 \%$ \\
\hline Total & $37.4 \%$ & $62.6 \%$ & $100.0 \%$ \\
\hline
\end{tabular}

One of the questions in the survey determined if students were using more features in Desire2Learn. Of the total number of respondents, $48 \%$ said they were using Desire2Learn more than Blackboard. The second question asked those who said they used Desire2Learn more than Blackboard for their reasons for using Desire2Learn more than Blackboard. The most common reason stated by $65.8 \%$ of those who said that they use Desire2Learn more than Blackboard was the "Ease of Integration." Table 6 below details reasons for the students' preference for Desire2Learn as opposed to Blackboard. Additionally, this question allowed for an open-ended response "Other." The responses for "Other” are listed below Table 6.

Table 6: Reasons for using Desire2Learn More

\begin{tabular}{ll}
\hline D2L: More Features & $\begin{array}{l}\text { \% who used } \\
\text { feature }\end{array}$ \\
\hline Training Options & $4.5 \%$ \\
Ease of Integration & $65.8 \%$ \\
Intuitive Interface & $16.2 \%$ \\
Other & $13.5 \%$ \\
Total & $100 \%$ \\
\hline
\end{tabular}

Other reasons why students used Desire2Learn more than blackboard are:

- More sophisticated features in grade book are available.

- Using profile pictures for students.

- The new functionality of the dropbox.

- Easier to navigate and learn about the features on Desire2Learn.

- $\quad$ Professors are posting more content on Desire2Learn making it more interesting.

Table 7: Usage of Blackboard and Desire2Learn Features

\begin{tabular}{lcc}
\hline Features & Blackboard & Desire2Learn \\
\hline Announcements & $53.3 \%$ & $59.3 \%$ \\
Syllabus & $63.0 \%$ & $65.4 \%$ \\
Discussion Board & $56.9 \%$ & $59.3 \%$ \\
Email & $37.8 \%$ & $39.0 \%$ \\
\hline Digital Dropbox & $53.7 \%$ & $59.8 \%$ \\
Quizzes and surveys & $63.8 \%$ & $64.2 \%$ \\
Group Tools & $14.6 \%$ & $11.0 \%$ \\
Collaboration (chat) & $7.7 \%$ & $6.1 \%$ \\
\hline Imbedded audio/video & $9.8 \%$ & $12.2 \%$ \\
Blackboard mobile & $2.0 \%$ & $7.7 \%$ \\
\hline Notification System & $15.0 \%$ & $16.7 \%$ \\
\hline Other & $2.4 \%$ & $2.0 \%$ \\
\hline
\end{tabular}


The questionnaire asked the students a series of questions to further determine the features used in both Blackboard and Desire2Learn to better understand if one technology was used more than the other. The students were presented with 12 features including an "Other" field which allowed for open-ended response. Desire2Learn was the preferred option for each of the features listed in Table 7, with the exception of the Group Tools and Collaboration (Chat). This breakdown is detailed in Table 7.

Those who responded using the option "Other" were given the opportunity to provide additional feedback on both systems. This feedback is summarized below for both Systems

1. Blackboard

- It is easier to find the "tabs" on the side bar which is broken down well. Much more user friendly. Also the ease of downloading or viewing files seems to be much easier when using Blackboard.

- $\quad$ Grades

2. Desire2Learn

- Grades are easier to read.

- The provided grading statistics show students how they did in relation to the class.

- The checklist function provides valuable extra information.

- The tabs are easy to locate.

\section{DISCUSSION}

The first research question was developed to determine the technology preferences between Blackboard and Desire2Learn from the perspective of the students. Based upon the results of the surveys and the information discussed in the previous section, these results can be discussed in one of two ways: (1) determining the technology preference overall and broken down by gender, age, education level, and degree or (2) Determining the percent usage of similar features in both system.

Based upon the results from the previous section, approximately $63 \%$ of the respondents said they preferred Desire2Learn, while just 37\% preferred Blackboard. These results were further broken down based upon other variables. With respect to gender, Desire2Learn was the preferred choice for both males and females. With respect to age each of the age groups preferred Desire2Learn with the exception of 56 - 65; this is probably an outlier since there was only one respondent in this age bracket and this person chose Blackboard. Desire2Learn also was consistently ranked higher in each level of education (Freshman, Sophomore, Junior, Senior, and Masters). Lastly, all degree categories ranked Desire2Learn as preferred over Blackboard with the exception of Information Systems/Information Technology which ranked Blackboard higher. It should be noted that there was no statistical significance between characteristics (gender, age, level of education, and degree) and the online class technology preference.

The second method to determine the technology preference for the online class was to compare the percent usage of similar features in both Desire2Learn and Blackboard. Of the 12 features listed, (including the "Other" feature), nine features were being used more in Desire2Learn as opposed to Blackboard. The two features that were used more in Blackboard as compared to Desire2Learn were Group Tools and Collaboration (Chat); it must be noted that these features had a low utilization percentage. Some students mentioned that Blackboard was organized better; however, other students thought Desire2Learn was organized better and it had advanced features that were available with grading. Clearly, Desire2Learn was preferred by a majority of students who took the survey in comparison to Blackboard.

The second research question focused on determining if a significant difference existed between the students' preferences for Blackboard and for Desire2Learn. The study did illustrate that the majority of features were used more in Desire2Learn as compared to Blackboard; however, this difference between the percent usage of each of these two technologies ranged from zero to six percent. This variance would not be considered significant. Instead, we conclude that Desire2Learn was preferred by students as their technology choice for their online classes but there was no statistical significance in their preferences for Desire2Learn as compared to Blackboard. 
Volume XII, No. 2, pp 273-280, 2011

\section{CONCLUSIONS}

The acceptance of technology is important for it to be successful. As many students chose Desire2Learn over Blackboard at this university, we realized that no technology is perfect. In order to keep up with the fast pace at which technology changes, universities must be willing to implement new tools and features in their online learning environment. Not keeping up with current technology for online education could be compared to a traditional brick and mortar school not having proper seating in a classroom. Universities should constantly modify their online environment and provide training to faculty and students to ensure that the application is used as it is intended.

\section{REFERENCES}

1. Allen, I, E., \& Seaman, J. (2010, November). Class differences. Online Education in the United States. Retrieved on 5/1/11 from http://sloanconsortium.org/publications/survey/pdf/class_differences.pdf

2. Blackboard Inc. (2000). Education benefits of online learning. A Blackboard tip sheet. Retrieved on March 22, 2011 from http://med.uth.tmc.edu/admministration/edu_programs/ep/blackboard/text/OnlineLearning_Benefits.pdf

3. The Center. (2006). Blackboard students survey report Winter 2006. The Center for Teaching and Learning at DU Faculty Advisory Board. Retrieved on April 15, 2011 from ctl.du.edu/support/blackboard/BbStudentReportWinter06.pdf

4. Chawdhry, A., Paullet, K., \& Benjamin, D. (2011). Assessing Blackboard: Improving online instructional delivery. Information Systems Educators Conference, EDSIG, 2011.

5. Hannay, M., \& Newvine, T. (2006). Perceptions of Distance Learning: A comparison of online and traditional learning. Merlot Journal of Online Learning \& Teaching. 2,(1) March 2006, 1-11.

6. Kovacs, P.J., Davis, G.A., Scarpino, J. \& Kovalchick, L. (2010. Student's perceptions of the effectiveness of various online learning formats as related to computer and information systems courses. IACIS, 2010.

7. Moore, J. (2010, April, 17). Blackboard to be replaced with Desire2Learn for fall 2010. The Snapper. Retrieved on 5/10/11 from http://thesnapper.com/2010/04/17/blackboard-to-be-replaced-with-desire2learn-for-fall-2010 